\title{
Exhaled nitric oxide and inhaled corticosteroid dose reduction in asthma: a cohort study
}

\author{
To the Editor: \\ Inhaled corticosteroids (ICS) reduce airway inflammation; however, guidelines recommend titrating ICS \\ dose based on symptoms [1], which are not closely associated with airway inflammation [2]. Once \\ symptoms are controlled for $\geqslant 3$ months, ICS reduction is recommended [3] but step-down is often not \\ implemented. Studies suggest that the majority of patients treated with ICS can have their therapy stepped \\ down, although there is no clear evidence on how best to achieve this [4].
}

We assessed whether exhaled nitric oxide fraction ( $F \mathrm{eNO}$ ) measurements could predict a loss of symptom control or exacerbation following a reduction in ICS dose in a cohort study of people with well-controlled asthma recruited from primary care.

All participants had a recorded asthma diagnosis, were aged 18-75 years, and had received at least one ICS prescription in the last year. The study was restricted to nonsmokers ( $<10$ pack-years). Poorly compliant participants, and participants with an asthma exacerbation requiring oral steroids in the previous 12 weeks or with a Juniper five-item Asthma Control Questionnaire (ACQ-5) [5] score $>1.5$ at visit 1 (indicating poor control) were excluded.

Participants were seen at the same time of day on four occasions: days 0, 14, 21 and 110. At each visit, ACQ-5, FeNO (Flex Flow; Aerocrine, Solna, Sweden) and spirometry were performed. Symptoms were assessed using the ACQ-5 [6]. Airway inflammation was measured using FeNO at $50 \mathrm{~mL} \cdot \mathrm{s}^{-1}$; participants were blinded to their measurements. Differential cell counts were performed on induced sputum. Spirometry was performed. Airway hyperresponsiveness was assessed using the concentration of methacholine required to provoke a $20 \%$ fall in forced expiratory volume in $1 \mathrm{~s}$ (PC20). Differential blood eosinophil count and IgE measurement were performed.

Participants were re-assessed at visit 2; if their ACQ-5 score remained $<1.5$ and had not increased by $>0.5$, their ICS dose was reduced by $50 \%$. Inhaler types were kept the same. Participants were asked to take the half dose of ICS for 7 days and then return for visit 3. At visit 3, the ACQ-5 score was re-measured.

A loss of control was defined as an increase in ACQ-5 score $>0.5$ (the minimal important difference in asthma control [7]). An exacerbation was defined as increasing asthma symptoms requiring a course of antibiotics or oral steroids [8]. All participants who contacted the emergency team were assessed by a physician within $24 \mathrm{~h}$ and their ACQ-5 recorded; decisions on treatment were based on British Thoracic Society guidelines.

We estimated that 154 subjects would provide $80 \%$ power to show that a low FeNO or lack of change in FeNO following ICS reduction could successfully predict stable control $[8,9]$. Data were analysed in two ways: firstly, we assessed whether a low baseline FeNO predicted successful ICS dose reduction; secondly, we evaluated whether an increase in FeNO following dose reduction predicted deterioration. We also evaluated whether other clinical measures predicted successful dose reduction at 3 months. Measures included: spirometry; methacholine PC20; IgE; blood eosinophil count; ACQ-5; and differential sputum eosinophil and neutrophil count.

191 participants had their FeNO level measured at before (visit 2) and 7 days after (visit 3) a 50\% reduction in ICS dose (visit 3) (table 1). 128 (67\%) participants completed the 3-month study period (after ICS reduction) with no loss of control or exacerbation, and $63(33 \%)$ out of 191 experienced either a loss of control $(n=32,17 \%)$ or exacerbation $(n=31,16 \%)$. The median (interquartile range) baseline ACQ-5 was $0.6(0.2-1.0)$ for the stable group and $0.8(0.2-1.0)$ for the deterioration group $(\mathrm{p}=0.53)$. The mean $\pm \mathrm{SD}$ ICS beclomethasone dipropionate (BDP)-equivalent dose reduction across the study was $363 \pm 267 \mu \mathrm{g}$.

There were no significant differences in baseline FeNO (visit 2) between those successfully reducing ICS dose and those suffering from a loss of control or exacerbation. At $50 \mathrm{~mL} \cdot \mathrm{s}^{-1}$, the geometric mean baseline FeNO 
TABLE 1 Baseline demographics presented for study population"

$\begin{array}{ll}\text { Variable Result } & \end{array}$

\begin{tabular}{|c|c|}
\hline Age years & $54.15 \pm 13.50$ \\
\hline \multicolumn{2}{|l|}{ Sex } \\
\hline Males & 83 (43.5) \\
\hline Females & $108(56.5)$ \\
\hline \multicolumn{2}{|l|}{ Age when diagnosed years } \\
\hline $0-5$ & $16(8.4)$ \\
\hline$>5$ & $175(91.6)$ \\
\hline \multicolumn{2}{|l|}{ BTS treatment step } \\
\hline 2 & $57(29.84)$ \\
\hline 3 & $111(58.12)$ \\
\hline 4 & $23(12.04)$ \\
\hline Smoking pack-years & $0(0-4)$ \\
\hline Height $\mathrm{cm}$ & $169.24 \pm 9.89$ \\
\hline Mass kg & $81.14 \pm 17.31$ \\
\hline $\mathrm{BMI} \mathrm{kg} \cdot \mathrm{m}^{-2}$ & $28.27+5.36$ \\
\hline BDP-equivalent ${ }^{\top}$ daily dose $\mu \mathrm{g} \cdot$ day $^{-1}$ & $400(200-1000)$ \\
\hline FEV1 L & $2.68 \pm 0.85$ \\
\hline FEV $1 \%$ predicted & $89.85 \pm 19.15$ \\
\hline FVC L & $3.65 \pm 1.00$ \\
\hline FVC $\%$ predicted & $99.81 \pm 16.87$ \\
\hline $\begin{array}{l}\text { Airway hyperresponsiveness } \mathrm{PC} 20 \mathrm{mg} \cdot \mathrm{mL}^{-1} \text { geometric mean } \\
(95 \% \mathrm{Cl})\end{array}$ & $8.02(6 . \overline{31}-10.17)$ \\
\hline Blood IgE kIU $\cdot L^{-1}$ & $91.5(28.50-253.50)$ \\
\hline Blood eosinophils $\times 10^{9}$ cells $\cdot \mathrm{L}^{-1}$ & $0.20(0.12-0.32)$ \\
\hline Sputum eosinophils \% & $0.80(0.25-4.75)$ \\
\hline Sputum neutrophils \% & $64.75(42.25-84.00)$ \\
\hline ACQ-5 score & $0.60(0.20-1.00)$ \\
\hline
\end{tabular}

Data are presented as mean \pm SD, $\mathrm{n}(\%)$ or median (interquartile range), unless otherwise stated. BTS: British Thoracic Society; BMI: body mass index; BDP: beclomethasone dipropionate; FEV1: forced expiratory volume in $1 \mathrm{~s}$; FVC: forced vital capacity; PC20: provocative concentration of methacholine producing a $20 \%$ fall in FEV 1 ; ACQ-5: five-item Asthma Control Questionnaire. ${ }^{\#}: \mathrm{n}=191{ }^{\top}{ }^{\top}$ : QVAR (Teva, Castleford, UK), 2:1 BDP; Flixotide (GlaxoSmithKline, London, UK), 2:1 BDP; budesonide, 1:1 BDP.

was $18.9 \mathrm{ppb}(95 \%$ CI $16.8-21.5 \mathrm{ppb})$ in the stable group and $19.7 \mathrm{ppb}$ (95\% CI 16.4-23.6 ppb) in the deterioration group $(\mathrm{p}=0.76)$.

There was no significant difference in the change in FeNO in the week following ICS reduction (visit 2 to visit 3 ) between the stable and deterioration groups. The mean $\pm \mathrm{SD}$ absolute change between visit 2 and 3 was $1.58 \pm 11.9 \mathrm{ppb}$ for the stable group and $1.03 \pm 14.88 \mathrm{ppb}$ for the deterioration group $(\mathrm{p}=0.80)$. There were no significant differences in any of the clinical measurements between groups.

Although guidelines recommend a 50\% reduction in ICS dose after 3 months of good symptom control, there is evidence of overtreatment with ICS [10] and a reluctance to reduce treatment [11]. Consequently, using inflammometry to guide treatment decisions may be beneficial. We addressed previous criticisms by evaluating both individual baseline FeNO and change from baseline. Neither baseline FeNO measurements nor change at 7 days following ICS dose reduction could predict which participants would remain stable or lose control over the next 3 months.

Participants were not blinded to their treatment allocation and a period of 7 days was used after step-down before repeating the FeNO measurements. This design was chosen to reflect real-life practice and for maximum future practical benefit. A $50 \%$ reduction was chosen as it is consistent with guideline recommendations. Our study was well powered to identify any change in FeNO values: the relationship between sputum eosinophilia and FeNO levels is strongest between 100 and $800 \mu \mathrm{g}$ ICS (BDP equivalent) [12]; previous studies have shown that ICS dose reductions less than the mean reduction in our study result in an increase in FeNO levels [13]; dose-dependent onset and cessation of action effects of ICS on FeNO levels have been demonstrated, with levels rising after one day of treatment reduction [14]; and the largest change in FeNO values is found at $400 \mu \mathrm{g}$ BDP [15], the mean value in our population. 
The lack of change in FeNO following dose reduction may reflect that: 1) FeNO measurements do not correlate well enough with airway inflammation in mild-to-moderate asthma; 2) ICS dose reduction was not large enough; and 3) the episodes of loss of control were not due to increased airway inflammation.

In addition to the failure to predict ICS reduction using FeNO, we found that none of the baseline clinical indices (induced sputum, methacholine responsiveness and spirometry) had predictive value for future stability following ICS step-down. This has important implications for ICS dose reduction and suggests better methods of identification of those at risk of a loss of control following ICS dose reduction are needed. 3 months http://ow.ly/A79aQ

Emma Wilson ${ }^{1}$, Tricia McKeever ${ }^{2}$, Beverley Hargadon ${ }^{3}$, Glenn Hearson ${ }^{1}$, John Anderson ${ }^{1}$, David Hodgson ${ }^{1}$, Helen Bailey ${ }^{1}$, Garry Meakin ${ }^{1}$, Mike Thomas ${ }^{4}$, Ian D. Pavord ${ }^{5}$, Tim Harrison ${ }^{1}$ and Dominick Shaw ${ }^{1}$

${ }^{1}$ Nottingham Respiratory Research Unit, University of Nottingham, Nottingham, UK. ${ }^{2}$ Dept of Epidemiology and Public Health, University of Nottingham, Nottingham, UK. ${ }^{3}$ Institute for Lung Health, Glenfield Hospital, Leicester, UK. ${ }^{4}$ Dept of Primary Care, University of Southampton, Southampton, UK. ${ }^{5}$ University of Oxford, Oxford, UK.

Correspondence: Dominick Shaw, University of Nottingham, Respiratory Research Unit, Clinical Sciences Building, Nottingham City Hospital, Hucknall Road, Nottingham, NG5 1PB, UK. E-mail: dominic.shaw@nottingham.ac.uk

Received: March 242014 | Accepted after revision: July 242014 | First published online: Aug 192014

Clinical trial: This study is registered at www.clinicaltrials.gov with identifier number NCT01308411.

Support statement: The study was funded by a grant from the UK National Institute for Health Research (NIHR). This paper presents independent research funded by the NIHR under its Research for Patient Benefit Programme (grant reference number PB-PG-1208-18175). The views expressed are those of the authors and not necessarily those of the UK National Health Service, the NIHR or the UK Department of Health. The NIHR had no role in study design, or collection, analysis and interpretation of data; or in the writing of the report; or in the decision to submit the paper for publication. The corresponding author had full access to all the data in the study and final responsibility for the decision to submit for publication.

Conflict of interest: None declared.

\section{References}

1 British Thoracic Society, Scottish Intercollegiate Guidelines Network. British Guideline on the Management of Asthma. A national clinical guideline. 2012 (revision). London, BTS, 2012.

2 Shaw D, Green R, Berry M, et al. A cross-sectional study of patterns of airway dysfunction, symptoms and morbidity in primary care asthma. Prim Care Respir J 2012; 21: 283-287.

3 Papi A, Nicolini G, Crimi N, et al. Step-down from high dose fixed combination therapy in asthma patients: a randomized controlled trial. Respir Res 2012; 13: 54.

4 Rank MA, Hagan JB, Park MA, et al. The risk of asthma exacerbation after stopping low-dose inhaled corticosteroids: a systematic review and meta-analysis of randomized controlled trials. J Allergy Clin Immunol 2013; 131: 724-729.

5 Juniper EF, Svensson K, Mork AC, et al. Measurement properties and interpretation of three shortened versions of the asthma control questionnaire. Respir Med 2005; 99: 553-558.

6 Juniper EF, O'Byrne PM, Guyatt GH, et al. Development and validation of a questionnaire to measure asthma control. Eur Respir J 1999; 14: 902-907.

7 Juniper EF, Bousquet J, Abetz L, et al. Identifying "well-controlled" and "not well-controlled" asthma using the Asthma Control Questionnaire. Respir Med 2006; 100: 616-621.

8 Shaw DE, Berry MA, Thomas M, et al. The use of exhaled nitric oxide to guide asthma management: a randomized controlled trial. Am J Respir Crit Care Med 2007; 176: 231-237.

9 Tattersfield AE, Postma DS, Barnes PJ, et al. Exacerbations of asthma: a descriptive study of 425 severe exacerbations. The FACET International Study Group. Am J Respir Crit Care Med 1999; 160: 594-599.

10 Diette GB, Patino CM, Merriman B, et al. Patient factors that physicians use to assign asthma treatment. Arch Intern Med 2007; 167: 1360-1366.

11 Hewitt RS, Modrich CM, Cowan JO, et al. Outcomes using exhaled nitric oxide measurements as an adjunct to primary care asthma management. Prim Care Respir J 2009; 18: 320-327.

12 Silkoff PE, McClean P, Spino M, et al. Dose-response relationship and reproducibility of the fall in exhaled nitric oxide after inhaled beclomethasone dipropionate therapy in asthma patients. Chest 2001; 119: 1322-1328.

13 Kharitonov SA, Yates DH, Chung KF, et al. Changes in the dose of inhaled steroid affect exhaled nitric oxide levels in asthmatic patients. Eur Respir J 1996; 9: 196-201.

14 Kharitonov SA, Donnelly LE, Montuschi P, et al. Dose-dependent onset and cessation of action of inhaled budesonide on exhaled nitric oxide and symptoms in mild asthma. Thorax 2002; 57: 889-896.

15 Jatakanon A, Kharitonov S, Lim S, et al. Effect of differing doses of inhaled budesonide on markers of airway inflammation in patients with mild asthma. Thorax 1999; 54: 108-114. 